\title{
A Smart Market for Nutrient Credit Trading to Incentivize Wetland Construction
}

John F. Raffensperger ${ }^{1}$, R. A. Ranga Prabodanie ${ }^{2}$, and Jill A. Kostel ${ }^{3}$

${ }^{1}$ RAND Corporation, 1776 Main St., Santa Monica, CA 90401. Email:

John_Raffensperger@rand.org. (Thiswwork is not a RAND output.)

${ }^{2}$ Department of Industrial Management, Faculty of Applied Sciences, Wayamba University of Sri Lanka, Kuliyapitiya 60200, Sri Lanka. Email: ranga@wyb.ac.lk

${ }^{3}$ The Wetlands Initiative, 53 W. Jackson Boulevard, Suite 1015, Chicago, IL 60604. Email:

jkostel@wetlands-initiative.org

\section{Abstract}

Nutrient trading and constructed wetlands are widely discussed solutions to reduce nutrient pollution. Nutrient markets usually include agricultural nonpoint sources and municipal and industrial point sources, but these markets rarely include investors who construct wetlands to sell nutrient reduction credits. We propose a new market design for trading nutrient credits, with both point source and non-point source traders, explicitly incorporating the option of landowners to build nutrient removal wetlands. The proposed trading program is designed as a smart market with centralized clearing, done with an optimization. The market design addresses the varying impacts of runoff over space and time, and the lumpiness of wetland investments.

We simulated the market for the Big Bureau Creek watershed in north-central Illinois. We found that the proposed smart market would incentivize wetland construction by assuring reasonable payments for the ecosystem services provided. The proposed market mechanism selects wetland locations strategically taking into account both the cost and nutrient removal 
efficiencies. The centralized market produces locational prices that would incentivize farmers to reduce nutrients, which is voluntary. As we illustrate, wetland builders' participation in nutrient trading would enable the point sources and environmental organizations to buy low cost nutrient credits.

Keywords: nutrient trading, wetlands, smart market, optimization, ecoservice pricing

\section{Introduction - nutrient trading and wetlands}

Water quality trading (WQT) is widely viewed as the most economical and efficient mechanism for controlling excess nutrient runoff loads in waterways. Nutrient runoff can be reduced cost-effectively using wetlands which also improve ecological sustainability. Recent research has pointed out the viability of WQT with wetlands as a supplier of nutrient credits (Heberling et al. 2010; US EPA 2007a). Though the capability of wetlands in removing nutrients is well established (Crumpton et al. 2006; Kadlec and Knight 1996; Kadlec and Wallace 2008; Reddy et al. 1999, 2005), only a few studies like Heberling et al. (2010), Ng (2007) and US EPA (2007a) have investigated the role of wetlands as credit suppliers in nutrient trading. US EPA (2007a) conducted a detailed analysis of the technical, economic, and regulatory aspects of WQT with wetlands, illustrating the need for further research into the integration of wetlands into WQT programs.

WQT, especially with wetlands, requires careful market design. Technical difficulties arise from nutrient transport dynamics of the watershed, spatial and temporal heterogeneity in the impacts of nutrient loading and uptake, and the uncertainty involved in nutrient transport and removal. From an economic standpoint, wetland construction requires lumpy investments and long-term land use commitments. Once constructed, a wetland would supply a seasonallyvarying series of nutrient reduction credits over a long time period, whereas the demand for nutrient reduction credits from point sources is relatively constant throughout a year. 
Wetlands remove various nutrients, such as nitrate-nitrogen and phosphorus, at different rates. In addition to the removal of excess nutrients, wetlands offer other ecosystem services or benefits, such as increasing wildlife habitat, improving biodiversity, and reducing flood damage. Ideally, the present value of a wetland should be determined by considering all these ecological services. Nutrient trading with wetlands should therefore accommodate multiple commodities such as nitrogen reduction, phosphorus reduction, and flood reduction.

Such complexities impede opportunities for efficient and fair trading in nutrient credits generated by wetlands. Trading mechanisms should be designed to encourage the voluntary participation of wetland builders. Unless the potential investors perceive wetland construction as a profitable long-term investment, they would not make the long-term financial and land use commitments required for wetlands.

WQT in the U.S. dates back at least to the 1980s (Eheart et al. 1987; O'Neil et al 1983; Shortle 2012), and has extensive literature covering market designs (Horan, Shortle \& Abler 2002; Hung and Shaw 2005; Morgan et al. 2000), market simulations (Horan et al. 2002; Leston 1992; Nguyen et al. 2013), case studies (Breetz et al. 2005; Fang et al. 2005), critical reviews (David 2003; King \& Kuch 2003; Kochtcheeva 1999; Stephenson and Kurt 2011), and detailed surveys (Environomics 1999; Morgan and Wolverton 2005; US EPA 2007b; US EPA 2008). Nitrogen and phosphorus are the most commonly traded nutrient pollutants in the U.S. Nutrient trading gained more attention as scientists identified the impacts of nutrients pollution, mainly algal blooms, hypoxia, and dead zones. At present, the U.S. has several watershed level nutrient trading programs in operation (Selman et al. 2009; Shortle 2012; US EPA 2008) targeting both point-point and point-nonpoint source trades. Though some WQT programs in the US facilitate the use of wetlands; only a few trades have actually taken place (Stephenson and Kurt 2011; US EPA 2007a). 
To date, U.S. nutrient trading has experienced both successes and failures, but failures dominate (Stephenson and Kurt 2011). The main reasons for failure are insufficient demand and supply caused by over-restrictive trading rules, few participants, and high transaction costs (David 2003; Faeth 2000; Hoag \& Hughes-Popp 1997; King \& Kuch 2003; McGartland 1988). The transaction costs arise because would-be buyers must find willing sellers, the physics of the proposed trade has to be appropriate, and the parties must usually obtain government approval.

Regarding the physics of the trade, most U.S. nutrient trading systems use trading ratios to manage the uncertainty in nonpoint source reductions (US EPA 2007b) and to account for the spatial differences in the impacts of point and nonpoint source reductions (Selman et al. 2009; Shortle 2013). These ratios are usually conservative, requiring a higher amount of nutrient reduction from nonpoint sources to offset point source discharges. Conservative trading ratios have been identified as a factor that impedes nutrient trading (US EPA 2007a). Some trading programs apply the same trading ratios for each trade between point and nonpoint sources, but fixed trading ratios do not accurately account for the spatial heterogeneity of nonpoint source impacts. Administrative cost rise when trading ratios are calculated separately for each trade. With trading ratios, a trade can occur through bilateral negotiations or through a third party (clearinghouse). While bilateral trading incurs high transaction costs, clearinghouses may incur higher administrative costs. Though several studies have focused on designing trading ratios (Shortle 2013), relevant scientific information has not been used in deciding trading ratios for real-time trades (Selman et al. 2009).

Besides trading ratio systems, various market designs applicable for nutrients have also been proposed. Zonal permit systems allow trades across time to account for the time lags in pollutant transport (Environmental Protection Authority 2003; Lock and Kerr 2008). 
Centralized auctions (Morgan et al. 2000) connect traders and an auctioneer through electronic media, use hydro-geological models to evaluate the impacts of trade, and attempt to find market equilibrium by adjusting prices iteratively. Smart markets (Prabodanie et al. 2014) use centralized clearing, various watershed hydrogeological models, and in particular, linear optimization algorithms to find market clearing prices, but smart market designs have not been tested for nutrient trading with wetlands. A detailed literature review on various nutrient trading systems is available in TWI (2014).

In this paper, we report on part of a major study done for the U.S. Environmental Protection Agency (US EPA) (TWI 2014), which explores the feasibility of using wetlands in a nutrient credit market. This project assessed whether the environmental, economic, and social factors could support a nitrogen and phosphorus credit trading market in the Big Bureau Creek (BBC) watershed, a sub-watershed of the priority Lower Illinois River-Lake Senachwine watershed. The project comprised (1) a full literature review, (2) an assessment for wastewater treatment plant demand and potential wetland site supply, (3) an economic analysis of a market, (4) development of a "smart market" proposal and simulation, (5) an assessment of the social readiness of stakeholders, and (6) specific proposals for administration of the market. Some of these sections have been published (Lentz 2011; Tomer et al. 2013; Lentz et al. 2013). This paper presents the design and simulation of the smart market (part 4) which we call "MarshWren." Our market design would assure economically justifiable payments for wetland builders, that the conservative ratio based trading has failed to accomplish.

A smart market is a periodic auction cleared with the help of mathematical optimization (Carlson et al. 2012; McCabe et al. 1991; Rothkopf et al. 1998). Owing to the use of an optimization model to clear the market (i.e., to determine the prices and quantities to be traded), smart markets are a viable trading mechanism that can account for complex physical 
interactions relevant to trade in common-pool commodities such as groundwater, electricity and pollution (Alvey et al.1998; Hogan et al. 1996; Prabodanie et al. 2014; Raffensperger 2008). As in a clearinghouse (Woodword et al. 2002), participants buy from or sell to a centralized auction manager rather than from or to each other. The auction manager aggregates all buyer bids and seller offers that become part of the optimization model. The optimization model chooses which bids and offers to accept while ensuring that required load constraints are satisfied at the minimum cost. After solving the optimization, the auction manager informs traders of the accepted quantities, collects money from buyers, and pays sellers based on prices obtained from the dual prices of the optimization. Under modest assumptions of competitiveness, the prices obtained from such an optimization model are expected to be efficient (Gabriel et al. 2005; Hobbs 2001; Samuelson 1952).

The smart markets, through the use of optimization models, can handle a range of complications that arise in nutrient trade with wetlands, including multiple types of commodities (nitrate and phosphorus), different attenuation rates in stream segments and wetlands, and multiple environmental constraints, while taking advantage of relevant scientific data that affect nutrient loads (e.g., precipitation, temperature, catchment area, and stream channel attenuation). Furthermore, the proposed smart market accounts for the lumpiness of wetland investments (i.e., the return does not linearly or continuously increase with the investment). The transaction costs of trading are likely to be low, so participants could trade easily and often, possibly online, at least once per season.

This point about transaction costs is an important one. Researchers often use optimization to simulate markets under the assumption of low transaction costs, resulting in wide participation, with predictably positive results. Assuming low transaction costs, a "perfect" market would find the optimum predicted by the optimization. Our simulation has this weakness, but to a much lesser extent than previous such simulations. Previous such studies 
simulate markets that are or would be cleared using ordinary bilateral exchanges, with high transaction costs. Our market design would be cleared with the same optimization used in our market simulation. The optimization matches supply and demand in many-to-many fashion, simultaneously with all participants. This design would reduce transaction costs, because users do not have to find their own trading partners; they simply trade directly with the market manager.

We simulated MarshWren for the BBC watershed. The simulation was based on data and analyses within the TWI project, including the Annualized Agricultural Nonpoint Source (AnnAGNPS) pollution model, nutrient loading results, and the estimation of wastewater treatment plant upgrade and wetland construction costs. Our results provide evidence that smart markets for nutrient trading would incentivize wetland construction by assuring economically justifiable payments for reducing nitrogen and phosphorus simultaneously over a long period. Among several simulated offers for constructing wetlands at selected feasible locations, the market clearing algorithm strategically selects wetland locations considering both cost and nutrient removal efficiencies. Trades driven by WWTPs alone cannot create an active market in the BBC watershed. Only a few wetlands are sufficient to offset the nutrient discharges of several WWTPs, and the trades would provide significant cost savings to WWTPs. The combination of wetlands and farm best management practices (BMPs) are the most economical way of reducing nutrients. Since the farm level reductions can be adjusted more dynamically compared to reductions from wetlands, temporal variations in demand may result in increased sales of farm BMPs, instead of some wetlands which require large initial investments. Therefore, our results illustrate the importance of farmers' participation in nutrient trading together with wetlands. Apart from nutrient removal, we did not consider other ecological benefits of wetlands; if those positive externalities could be internalized, the market would perform even more effectively. 
In the next section, we describe the proposed smart market design in detail. Section 3 summarizes the theoretical context underlying the proposed market. The BBC watershed case study is presented next, followed by a simulation of the proposed smart market for the BBC watershed. The results section includes an analysis of the simulation results, followed by our conclusions.

\section{Materials and Methods: MarshWren Market Design}

We first identify the market participants, the commodities being traded, market rules, and operational procedures. We use the term "market" to refer to the whole design and its behavior. The term "auction" refers to an instance of market operation, where the participants submit bids and offers, and the market manager clears the market.

\subsection{Market participants}

The parties directly interacting with the market are the regulator who sets up and oversees the market, the market manager who operates the auctions, and the traders who buy and sell nutrient credits.

Regulator. The regulator is a governmental oversight party which is responsible for implementing and overseeing the trading system. Owing to the public nature of fresh water resources, a level of government oversight will be required in any allocation mechanism.

Market manager. The regulator should appoint and oversee the market manager, who is responsible for operating the market, has to keep records of nutrient credit ownership and transfers, maintain the watershed hydrology data, and operate the auction website and clearing optimization. Participants trade through a common pool of nutrient credits managed by the market manager, so the traders implicitly buy from or sell to the market manager. 
Traders. Market participants include municipal or privately owned permitted treatment facilities which discharge nutrients into the stream, mainly WWTPs as point sources, farmers or landowners who apply nutrients on land as nonpoint sources, investors or landowners who are willing to construct nutrient removal wetlands as wetland builders, and environmental authorities or non-government organizations who would like to pay the nutrient dischargers (nonpoint sources that are not regulated) to reduce nutrient runoff from the watershed as environmental agents.

We assume that each point source has a permit that specifies the load limits, the maximum allowable total nitrogen and total phosphorus load discharged per day. Demand can arise when a point source finds it costly to meet its permitted discharge levels. To achieve regulatory acceptance of an existing excess discharge, the point sources can buy nutrient reduction credits from the market manager, as long as the market manager can match purchases to willing sellers. Technology-based effluent limits (TBELs) may restrict the amount of nutrient reductions that a point source can buy; the regulator may require the point source to meet these TBELs before the point source can purchase credits to meet water quality-based effluent limit (WQBEL). Such trades may not significantly reduce nutrient runoff in watersheds where nonpoint sources are responsible for most of the load. Fortunately, MarshWren allows the participation of environmental authorities and other interested groups who may wish to reduce the load by buying nutrient credits from potential sellers such as wetland owners and farmers.

Investors who plan to construct or restore wetlands to capture and reduce nitrogen and phosphorus loads into the stream network can participate in the trading program as nutrient credit suppliers. Farms that implement BMPs, such as nutrient management or cover crops, can generate nutrient credits and participate in the market as credit suppliers. 
The locations of the participants, particularly the discharge points, are important for nutrient trading. We assumed that each point source discharges to a single stream segment, and that each nonpoint source is in the drainage area of one stream segment. A large farm contributing to two or more stream segments can be considered (virtually) as separate farms submitting separate offers for each segment. Any environmental agent can buy nutrient reductions on any stream segment. An environmental agent who wants to buy credits on two or more segments can be considered (virtually) as separate traders.

\subsection{What is traded?}

MarshWren allows trade in multiple commodities: rights to discharge nitrogen and phosphorus in various time periods. We define a tradable nutrient credit as a legal document conferring to its owner the right to discharge 1 kilogram of a particular nutrient for one season in a particular year. Since non-degradation is considered as a basic requirement of trading, which should always be satisfied before any quality improvement can be achieved, all tradable nutrient credits must be earned through nutrient reductions. Each credit document specifies the season, year, and nutrient type (i.e., nitrogen or phosphorus); credits expire after one season.

Farmers and WWTPs can trade nutrient credits directly based on kilograms by season, but people who offer to build wetlands cannot control nutrient reductions by season. They can only offer to construct a wetland of a particular size and configuration at a particular place, at a specified cost. This is similar to offering a single price for a bundle of credits for several nutrients and seasons. Point sources and environmental agents bid to buy credits for a particular nutrient, season, and a year. In contrast, wetland builders offer to sell bundles of credits for sets of nutrients, seasons, and years. Matching the demand for separate products and supply of bundles of products, with varying configurations, is not obvious (among other 
complexities in the watershed nutrient transport dynamics). Under such complexity, the market design must satisfy several key requirements.

\subsection{Market requirements}

TMDL or Cap. The market requires pre-determined caps on the total nitrogen and total phosphorus loads from the watershed. A TDML (total maximum daily load) usually specifies the maximum sustainable nitrogen or phosphorus load from the watershed as measured at one or more assessment points, such as the outlet of the watershed. To avoid local pollution, the regulator may impose TMDLs on several stream segments (thus having several assessment points), which MarshWren can easily accommodate as additional constraints.

Initial allocation. The market requires that each point and nonpoint source have an initial allocation. This initial allocation is the source's pre-trade maximum allowed discharge level, which can be zero. It is important to see that this initial allocation is not part of our market design. The regulator must choose the initial allocations before any trade can occur.

We point out a few simple methods that the regulator could use. First, the regulator could distribute the TMDL equally among all identified users. Equal initial allocations may be unfair when different sources operate at different scales, e.g., large farms and small WWTPs; some may get excess allocation while some are in shortage. Second, the regulator could set a user's initial allocation equal or proportional to the user's current runoff. See Raffensperger (2011) for various other methods of initial allocation.

Given the current US policy towards the management of agricultural nutrient discharges, we had little ability to select an optimal method of initial allocation. Since farmers are not regulated, their runoff rights seem to be unlimited, while WWTPs are restricted by discharge permit limits or a TMDL. If farmers want to be paid for reductions, they would be motivated 
to agree on some initial level from which the reductions can be calculated. Therefore, we assumed the current runoff from each point and nonpoint source as an initial allocation.

If the farmers knew beforehand that their initial endowment would be set to the current runoff, they would have a perverse incentive to increase their runoff prior to market implementation. The regulator could define a farmer's initial endowment based on the farmer's historical and current land use type, rather than the present application of nutrients. Some watershed level studies (for ex., Weeds et al. 2004) have developed formulae to calculate nutrient loss from various agricultural land uses. Watershed pollution models such as AnnAGNPS (Annualized Agricultural Nonpoint Source), which we used in the TWI project, estimate the nutrient loading from each model cell based on land use patterns and hydrogeology. Such tools must be used to make a reasonable estimate of current runoff avoiding the impacts of purposeful manipulations. In any case, implementers will need to take care in how they coordinate setting of initial rights at the start of the market.

Wetland characteristics. The proposed wetlands must have some agreed-on removal ability, which is part of the offer. Wetland owners cannot easily control the load removed, as load is a function of upstream inputs, flow, and wetland physical parameters. However, the regulator can measure the amount of nitrogen or phosphorus by monitoring concentrations and flows at the inlet and outlet, which can be costly, or the regulator can license the wetland with a specific seasonal nutrient removal rate that takes into account seasonal variations. While seasonal removal rates can account for the impacts of varying environmental conditions such as temperature and flow rates, the removal rates may decrease over time. Our market design can account for decreasing removal efficiencies, because it can consider different absorption rates for each trading period (e.g., X kg in year 1 winter, $0.95 \mathrm{X} \mathrm{kg}$ in year 2 winter, and so on). 
Specification of BMPs. Just as wetland owners cannot easily control the load removed, farmers cannot easily control their runoff. While farmers submit quantitative offers for reductions, such offers must be associated with agreed-on BMPs. Achieving a target level of reduction may need a combination of nutrient management BMPs (e.g., fertilizer management, cover crops, conservation tillage) and structural BMPs (e.g., riparian buffers, grassed waterways), as these practices have different impacts on nitrogen and phosphorus runoff. Before implementation, the regulator can estimate a set of standard BMPs and their associated reduction efficiencies at the watershed scale. The farmers can use this information to derive and submit quantitative offers based on the BMPs that they wish to implement. As discussed in section 2.5 below, the regulator must monitor the BMPs, since it is difficult to measure the reductions directly.

In addition, the market model should include data on stream network configuration, natural attenuation in each stream segment, and locations of the offered wetlands and the farms offering BMPs.

Trading horizon. The proposed market operates as a periodic auction. The timing of the auctions is important. The participants would like to trade with a frequency matching their ability to control nutrient discharge. WWTPs can usually partially control their emissions on a daily basis, but can also change their technology to get step changes in their emissions. The farmers would want to trade once per season, timed with their fertilization and cropping program. Constructing or restoring a wetland is a long-term capital and land-use commitment. Wetland builders cannot change the wetland configuration each season. Before making a commitment, they would seek an assurance of payments for their services over a number of years. 
Thus, the market manager should determine the length of the trading period and the number of periods (for which trading is allowed) based on how often the participants can change their land use practices and the variations in the environmental conditions.

Though the wetland builders may prefer a long trading period like $20-50$ years, we selected a seasonal auction calendar that allows trading futures for the following 10 years, i.e., $4 \times 10$ trading periods, with each period corresponding to a season. A key purpose of this futures auction is to incentivize landowners to invest in wetland construction. This design would generate the funds to cover the fixed cost of wetlands.

The wetland builders offer bundles of credits, including futures for all 40 seasons. However, farmers and WWTPs may wish to adjust their holdings in every season. MarshWren allows this, because in each season, farmers and WWTPs can change their previously-traded positions. However, if the market manager accepts an offer to build a wetland, the seller must build it immediately and maintain it throughout the whole 40 periods.

\subsection{Market operation}

The market will operate as an online auction. The market manager will call for bids and offers at the beginning of each season. Participants can submit bids and offers online to trade nutrient credits for the following 40 seasons (4 seasons over 10 years).

Point sources could trade nutrient credits for each of the 40 future seasons separately. Bids/offers $(\$ / \mathrm{kg} \mathrm{N}$ or $\mathrm{P})$ submitted by a point source for different seasons are independent, and hence, different quantities can be accepted for different seasons. The farmers could submit separate offers for each season, or a single offer for multiple sequential seasons, possibly intending to invest in long-term nutrient reduction projects (e.g., buffer strips or grassed waterways). In our simulations, we assumed separate offers for each season. Wetland builders submit a single offer (\$) to construct a wetland, which supply nutrient credits at 
agreed rates ( $\mathrm{kg} / \mathrm{season})$ at an agreed location for the 40 season period; each season can have a separate nutrient removal rate.

After receiving the bids and offers, the market manager enters them into the market clearing optimization model, and solves it with a standard linear programming algorithm. The solution determines the optimal quantities to be traded by each participant and the prices at each node. Each participant will face the price at their local downstream node. Since each participant contributes to and/or reduces the nutrient load on a particular segment of the stream network, each participant is trading reductions on that particular segment. Constraints in the model ensure that the total nutrient load from the watershed remains within the pre-determined cap or TMDL. Owing to in-stream attenuation, the buy and sell quantities may not balance exactly. For example, a purchase (increase) of $100 \mathrm{~kg} \mathrm{~N}$ at an upstream node with attenuation of $5 \%$ along the stream segment could be offset by a sale (decrease) of only $95 \mathrm{~kg} \mathrm{~N}$ at the downstream node.

Following auction clearing, the market manager collects money from buyers and pays sellers at their respective nodal prices. The market manager immediately settles payments for future credits. Wetland builders with accepted offers receive immediate payment to construct the wetland. ${ }^{1}$ The market manager has the option of holding a portion of the payment owing to the wetland builder to ensure compliance.

The market operates as a "futures" auction where participant trade credits for a relatively long period ahead. It has close analogy to forward capacity markets (FCM) in electricity, which enable retailers to buy capacity options (Cramton and Stoft 2008). FCM serves several

\footnotetext{
${ }^{1}$ Wetland construction and vegetation establishment (start-up period) can take 12-18 months. The market development and initial bidding can occur prior to NPDES permit issuance to ensure the credits are available when needed, or fewer credits can be offered during the period when the wetland is "coming on line" during the 10-year auction period.
} 
purposes, including increasing the reliability of supply and generating funds to cover the fixed cost of capacity investments, just as our proposed market would generate funds to cover the fixed cost of wetland construction. FCMs bring together suppliers like nuclear power plants which can supply power at relatively constant rates, and gas fired generators which can supply at varying rates. Similarly, our market brings together the wetlands which can supply reductions at a relatively constant rate and farm BMPs which can supply reductions at variable rates.

Compared to the existing process of bilateral trades, trading through the smart market would be far more convenient for traders. The regulator could choose to require all trades to go through the smart market, or could continue to allow bilateral trading. Bilateral trades would still have to be approved by the regulator or the market manager, who would incur an extra cost, and may decide to charge for it.

We note that a WWTP could build its own wetland and discharge into it, to avoid paying into the market. The regulator would have to agree on the nutrient removal capability. If the removal capability of such a wetland were in excess, the wetland owner could sell the excess credits to the market. This should be allowed, just as the WWTP should be allowed to upgrade its technology.

\subsection{Monitoring and enforcement}

Once the market is cleared for a given season, participants must comply with their agreements for the current season. Though point source emissions can be measured easily, the regulator may not be able to accurately measure the nutrient reductions from farm BMPs. The regulator may be able to use nutrient monitoring sensors on the farms or in-stream, but measuring actual farm loading accurately may not be possible. Instead of monitoring the 
reductions, the regulator could inspect the land use practices specified by the BMP. Better monitoring may be achieved via a combination of sensors and inspections.

The wetland credit traders are responsible for the performance of wetlands. If a wetland does not perform as agreed, that is non-compliance, and the regulator should enforce the responsible party to do the required expansion, maintenance, or improvement. The regulator can monitor wetland performance with sensors at inlet and outlet. The market manager can withheld a portion of the total payment due to a wetland builder and make some seasonal payments to ensure compliance.

In general, the regulator should monitor in-stream concentration to verify that the expected reductions are actually taking place. Observations at different locations will provide insight about the impacts of newly implemented BMPs and wetlands. The regulator can also use this data to calibrate the models used to estimate farm nutrient runoff and wetland absorption rates.

\section{Theoretical context}

Smart markets encompass the economic theory and the dynamics of the physical systems which convey, generate or consume the commodities being traded.

In a competitive market, with a large number of players (producers and consumers), demand and supply determine the prices. In our case, the bids to buy and offers to sell resemble an approximate piece-wise linearization of the demand and supply functions (Figure 1). The intersection of these bid and offer functions, as shown in Figure 1, corresponds to the prices and quantities which maximize consumer and producer surplus (Samuelson, 1952). The prices will be "efficient" to the extent that these bids and offers reflect actual consumer benefits and producer costs (Gabriel et al. 2005; Hobbs 2001; Samuelson 1952) for the traded commodities. The linear program, which we use to clear the market, finds this optimal level 
of trade, subject to constraints which represent the physical system (the capacity of a wetland to absorb nutrients, the relationships between the nutrient loads at upstream and downstream nodes, etc.). This concept has been adopted in trading electricity (Alvey et al.1998; Hogan et al. 1996), water rights (Raffensperger 2008), emission rights (Prabodanie et al. 2014), and other commodities.

Figure 1: Marketing clearing using a linear programming optimization model.

\subsection{Locational marginal cost pricing}

Locational marginal cost pricing is a key feature of MarshWren. Since nutrient reductions have different impacts at different locations, traders should see different prices at different locations. The clearing mechanism should consider the stream network configuration and attenuation in finding locational prices. These prices come from the shadow (dual) prices of the nodal load balance constraints, following standard optimization theory. If the bids and offers indicate the true marginal cost of reductions, the nodal prices obtained from such an optimization model can be considered as efficient market clearing prices (Gabriel et al. 2005; Hobbs 2001; Samuelson 1952).

With a marginal cost based pricing approach, accepted buyers pay their bid price or less; accepted sellers receive their offer price or more; both enjoy economic surplus. Thus the participants can bid/offer truthfully without disguising their costs, and would face a fair "going rate."

Each point and nonpoint source is charged or paid at the nodal price, the price at the nearest downstream node, but the prices for wetlands will be somewhat different. The former will face standard marginal cost nodal pricing, while the latter face "start-up" pricing. 


\subsection{Wetland pricing}

Compared to other farm BMPs, the construction of a tile-drainage treatment wetland is a large capital investment. A landowner is unlikely to make that investment prior to his/her offer being accepted. While wetland management can impact nutrient removal, nutrient removal is mainly determined by incoming nutrient load and the physical design parameters (i.e., wetted area, depth, shape, vegetation type). The landowner offering to build a wetland may not be able to significantly change the offered configuration, size, or position of the wetland, and therefore cannot change its nutrient removal capacity. This introduces discreteness to the decision, requiring binary decision variables in the market clearing optimization model.

To accommodate the discrete choices associated with wetland construction, we adopted a method originally developed by O'Neill et al. (2005). They first solved the optimization with binary variables as a mixed integer programming problem (MIP). Then they solved an augmented linear program (LP) with only continuous decision variables, and additional constraints to force the previously binary variables to their optimal value in the MIP solution. The dual prices of the augmented LP solution provide both the nodal credit prices and "startup" prices for accepted wetlands. (Alternatively, the market manager could use other approaches, such as the average shadow price method (Liao et al. 2009) to handle the "all-ornothing" nature of wetland offers.)

For an accepted wetland, the wetland builder will receive payments for nutrient reductions at the respective nodal prices. Additionally, the wetland builder may receive a start-up payment. If the total payment for reductions equals or exceeds the offer price, the start-up payment will be $\$ 0$. Otherwise, the start-up payment will be sufficient to raise the total payment to match the offer price. 
Unfortunately, O’Neill prices cannot guarantee revenue neutrality (the total payment due to the sellers may be greater that the total payment due from buyers). This occurs in MarshWren when a partially demanded wetland is fully accepted. This problem can be overcome in several ways, such as by the regulator choosing to cover the small shortage from a small reduction in initial rights that would increase the revenue (Raffensperger, 2011).

\subsection{MarshWren optimization model}

For market clearing, the market manager would solve the linear program below, with participant bids and offers, first as a MIP and then as an LP. As we explain below, part of the solution for the MIP model becomes input to the LP model. We used a spreadsheet as a frontend to enter the data and to run the optimization model. We used open source software, OpenSolver.xlsm and SolverStudio available at opensolver.org to model and solve the optimization.

\section{Indices}

$i, j=$ nodes in the stream network. A stream segment is identified by two nodes, upstream and downstream respectively. A potential wetland site is also identified with two stream nodes, upstream and downstream of the wetland respectively.

$u=$ trader; for point and nonpoint source traders, $u \in j$ implies that trader $u$ 's nearest downstream node is $j$. For wetland traders, $u \in j$ implies that the offered wetland's downstream node is $j$. For environmental agents, $u \in j$ implies that trader $u$ is trading credits on node $j$.

$t=$ season.

$n=$ nutrient type, 1 for nitrogen and 2 for phosphorus.

\section{Parameters}

$A_{(i, j), n, t}=$ percentage of natural attenuation of nutrient type $n$ on stream segment $(i, j)$. 
$\alpha=$ fraction of current runoff allowed. $(1-\alpha)$ is the target nutrient reduction at the assessment point as a percentage of current nutrient load.

$D_{u, n, t}=$ trader $u$ 's current $\mathrm{kg}$ load of nutrient $n$ received at the nearest downstream node in season $t$. The model takes the current load as a status quo, and treats it as an initial right. We assume that the nonpoint source traders will not exceed this initial allocation at least until next auction for which the status quo can be adjusted.

$G_{j, n, t}=$ current kg load of nutrient $n$ received at node $j$ in season $t . G_{j, n, t}=\sum_{u \in j}\left(D_{u, n, t}\right)+$ $\sum_{k \mid(k, j) \in \text { str. segments }}\left(1-A_{(k, j), n, t}\right) G_{k . n, t}$.

SellPrice $_{u, b, n, t}$, BuyPrice $_{u, b, n, t}=$ offer or bid price of trader $u$, step $b$, nutrient $n$, season $t$. Bids and offers will be accepted in steps, for example, $\$ 2 / \mathrm{kg}$ for the first $10 \mathrm{~kg}$ of reductions, $\$ 5 / \mathrm{kg}$ for the next $12 \mathrm{~kg}$ of reductions, and so on.

SellQty $y_{u, b, n, t}, B u y Q t y_{u, b, n, t}=$ offer or bid quantity of trader $u$, step $b$, nutrient $n$, season $t$.

$T=$ number of periods in the auction model, e.g., 40 seasons (10 years).

WPrice $_{u}=$ offer price of trader $u$ offering to build a wetland.

$W A_{u(l, m) n, t}=\mathrm{kg}$ reduction/removal of nutrient $n$ from the particular wetland segment $(l, m)$ in season $t$ if trader $u$ builds the offered wetland at the beginning of season 1 .

\section{Decision variables}

$q_{u, n, t}=$ post-trade credit allocation to trader $u$ for nutrient $n$ in season $t$.

$x_{i, n, t}=\mathrm{kg}$ load of nutrient $n$ at node $i$ in season $t$.

$w_{u(l, m)}=1$ if trader $u$ 's offer to build a wetland on segment $(l, m)$ is accepted, otherwise 0 . We will use the notation $w_{u}{ }^{*}$ to indicate the optimal values of $w_{u}$ in the mixed integer program.

$\operatorname{sell}_{u, b, n, t}, \mathrm{buy}_{u, b, n, t}=$ accepted sell and buy quantities respectively, for trader $u$ and bid step $b$ of nutrient $n$ in season $t$. 


\section{Model MarshWren}

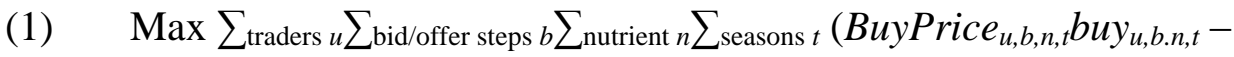
SellPrice $_{u, b . n, t}$ Sell $\left._{u, b . n, t}\right)-\sum_{\text {traders } u}$ WPrice $_{u} w_{u}$,

subject to:

(2) $\quad q_{u, n, t}=D_{u . n, t}+\sum_{\text {bid/offer steps } b}\left(b u y_{u, b . n, t}-\operatorname{sell}_{u, b . n, t}\right)$, for each non-wetland trader $u$, nutrient $n$, and season $t$.

(3) $x_{j, n, t}=\sum_{\mathrm{p} / \mathrm{np} \text { trader } u \in j}\left(q_{u, n, t}\right)+\sum_{k \mid(k, j) \in \text { str. segments }}\left(1-A_{(k, j), n, t}\right) x_{k . n, t}+\sum_{l \mid(l, j) \in \text { wet. segments }}\left(x_{l \cdot n, t}-\right.$ $\left.W A_{(l, j), n, t} w_{u(l, m)}\right)$ for each node $j$ except leaf nodes, nutrient $n$, and season $t$. Dual price $p_{j . n, t}$

(4) $\quad x_{\text {last.n, } t} \leq \alpha G_{\text {last }, n, t}$ for the assessment point node last, each nutrient $n$, and season $t$. Dual price $p_{\text {last. }, t}$

(5) $0 \leq$ buy $_{u, b, n, t} \leq$ BuyQty $_{u, b, n, t}, 0 \leq$ sell $_{u, b, n, t} \leq$ SellQty $_{u, b, n, t}$, for each trader $u$, bid step $b$, nutrient $n$, and season $t$.

(6) $q_{u, n, t}$ free for each trader $u$, nutrient $n$, and season $t ; x_{j, n, t} \geq 0$ for each node $j$, nutrient $n$, and season $t$.

(7a) In the first (mixed integer programming) model, $w_{u}$ binary.

(7b) In the second (linear programming) model, $w_{u} \leq w_{u}{ }^{*}$ if $w_{u}{ }^{*}=0$, and $w_{u} \geq w_{u}{ }^{*}$ if $w_{u}{ }^{*}=$ 1 , for all $u$. Dual price $\omega_{u}$.

(8) $\quad 0 \leq w_{u} \leq 1$, for all $u$.

\section{Explanation}

(1) The bid and offer prices are the coefficients of the objective function. These values indicate the value of each block of nutrient reduction to the trader. Hence, the objective function maximizes the total gains from trade. If the bid and offer functions indicate the true 
marginal cost of nutrient reductions, the objective function also maximizes the true social welfare, the consumer and producer surplus.

(2) This constraint set calculates the post-trade credit position of non-wetland traders by adding the net purchases to the initial position.

(3) This constraint set calculates the post-trade load of nutrient $n$ at each node $j$ in each season $t$. The dual price $p_{j, n, t}$ which reflects the marginal cost of nutrient reduction at node $j$, gives the nodal price of nutrient $n$ at node $j$ in season $t$. Traders whose nearest downstream node is $j$ face the price $p_{j, n, t}$. Due to in-stream attenuation, prices can vary along the stream. The adjusted prices of the stream nodes are given by the shadow prices of constraint 3 .

(4) This constraint set ensures that the total load at the assessment point does not exceed the seasonal load limit. This is the "water quality constraint" which drives nodal prices. The price $p_{\text {last }, n, t}$ of this constraint indicates the marginal cost of the last unit of reduction required to meet the load limit at the assessment point . Hence, $p_{\text {last }, n, t}$ is the right market price per kg of credit at the assessment point. This price matches supply and demand, maximizing gains from trade. We used $G_{l a s t, n, t}$ as the total "worst case" nutrient load at the assessment point, which corresponds to the status-quo. If $\alpha=1$, the seasonal load limit equals current total load, with no reduction required. When $\alpha=0.6$, the seasonal load limit corresponds to a $40 \%$ reduction requirement.

(5) The quantity accepted from each bid/offer block cannot be negative; the upper bound on each bid/offer step ensures that the traded quantity does not exceed the maximum specified by the trader.

(6) The non-wetland traders cannot sell beyond the initial credit position, so $q_{u, n, t} \geq 0$.

However, we set $q_{u, n, t}$ to be free to avoid dual degeneracy. Nutrient load at each node cannot be negative. 
(7a) The decision variable corresponding to the acceptance or rejection of each wetland is binary, indicating that the offer cannot be partially accepted (i.e., the trader cannot build a partial wetland). However, this binary integrality constraint is relaxed when solving the model as an augmented linear program, when constraint sets $7 \mathrm{~b}$ and 8 are added.

(7b) These constraints are included in the augmented optimization as proposed by O'Neill et al. (2005). First, a MIP is solved with 7a and without 7b and 8. Second, a LP is solved without $7 \mathrm{a}$ and with $7 \mathrm{~b}$ and 8 . The dual price $\omega_{u}$ is the one-off payment faced by the wetland builder $u$ for constructing and maintaining the offered wetland.

(8) This constraint set imposes lower and upper bounds on the decisions associated with wetland offers.

The optimization model is quite general allowing almost anyone to buy and sell nutrient credits in a fully pledged double-sided auction. But since the BBC watershed is already overloaded with nutrients, we simulated the auctions under various assumptions as discussed in section 5 .

\section{Big Bureau Creek Case Studies}

The Big Bureau Creek (BBC) watershed lies in north-central Illinois. The BBC watershed drains approximately 129,000 ha to two backwater lakes that flow into the Illinois River. The land cover is dominated by agriculture (92\%) with relatively little developed area. Runoff from agricultural nonpoint sources and point sources have contributed to the degradation of water quality in the watershed. Available data provide evidence that this watershed is carrying significant levels of nutrients, mainly nitrogen, to the Illinois River (TWI 2014). According to BBC Watershed Group (2008) estimates, 1,680 metric tons of nitrogen and 60 metric tons of phosphorus leave the watershed outlet annually. 


\subsection{The need for nutrient trading in $\mathrm{BBC}$}

According to TWI (2014) estimates, the total nitrogen (TN) and total phosphorus (TP) loads at the $\mathrm{BBC}$ outlet correspond to mean annual concentrations of $6.4 \mathrm{mg} / \mathrm{l}$ of $\mathrm{TN}$ and $1.16 \mathrm{mg} / \mathrm{l}$ of TP. Both exceed the threshold criteria of $2.18 \mathrm{mg} / \mathrm{l}$ for TN and $0.076 \mathrm{mg} / \mathrm{l}$ for TP recommended by US EPA (2000). Illinois authorities, similar to most other states, attempt to control nonpoint source nutrient discharges through voluntary initiatives such as education and federal and state financial assistance for conservation practices.

The need for nutrient trading in BBC arises from two key factors. First, the point sources collectively account for less than $1 \%$ of TN and TP runoff from the watershed. Second, with current US regulations, the regulator cannot impose numerical standards on agricultural nonpoint sources, though they contribute $99 \%$ of the nutrient runoff from the watershed. The only way to reduce the nutrient load significantly is for WWTPs to buy their required reductions and another party buy additional reductions from farmers or from third parties such as wetland builders. We have already discussed in section 1 why a smart market is most appropriate for nutrient trading with wetlands.

\subsection{BBC network description}

Figure 2 shows a representative part of the BBC stream network. Each stream segment is identified by an upstream and a downstream node. ArcHydro tools were used to model the stream network, with nodes at each headwater segment and at each stream intersection. The tools assign a from-node and a to-node to each segment to indicate flow direction. The stream network initially consisted of 1,838 nodes. Then we identified 80 potential wetland locations using the wetland siting methodology developed as part of TWI (2014).

The wetland siting methodology uses GIS and Public Land Survey data to evaluate the feasibility of each square-mile section to become a wetland (Lentz 2011a). It selects wetland 
sites based on three criteria. The first criterion ensures that water drains into a potential wetland, by selecting only those sites with a positive topographical positioning index (TWI 2014). The second criterion ensures that only sites within $100 \mathrm{~m}$ of a stream are selected. The third criterion eliminates the sites located on land use classes such as urban areas where conflicting interest would prevent wetland construction.

We manually inserted nodes for the inlets and outlets of those potential wetland sites. Segments refer either to an ordinary stream segment or to a wetland, with the wetland segment having a much greater attenuation than an ordinary stream segment.

Figure 2. Example of the Big Bureau Creek stream network configuration.

\subsection{BBC hydrogeological data}

Illinois has not established water quality standards for rivers and streams, and has not approved a TMDL for nitrogen and/or phosphorus for BBC or its subwatersheds. We therefore used the current nitrogen and phosphorus load from the watershed (Table 1) as a baseline and we designed the trading program to achieve a pre-determined percentage or load reduction at the watershed outlet. These assumptions are not a fault of our market design, but rather examples as to what a regulator might do on implementing the market.

Table 1. The estimated current TN and TP loads at the BBC outlet (TWI 2014).

\begin{tabular}{lcccc}
\hline Season & winter & spring & summer & autumn \\
\hline TN current runoff, kg & 246,086 & 965,653 & 819,694 & 422,275 \\
\hline TP current runoff, kg & 43,197 & 178,250 & 147,432 & 66,347
\end{tabular}

We used the AnnAGNPS model as described in TWI (2014) to determine the seasonal nitrogen and phosphorus removal capabilities of each potential wetland. AnnAGNPS calculated the impact of each wetland, assuming that all 80 proposed wetlands were implemented. We modified the standard output to calculate the independent impact of each wetland assuming no other wetland on the same reach. According to AnnAGNPS estimates, 
the BBC stream network had little natural attenuation of nitrogen and phosphorus in all seasons (less than $1 \%$ in-stream attenuation from headwaters to the BBC outlet). As a conservative measure, we randomly assigned small attenuation factors $(0 \%, 0.25 \%, 0.50 \%$, or $1 \%)$ to all the non-wetland segments.

\subsection{BBC traders}

Of the fifteen privately and publicly owned WWTPs in the BBC watershed, only nine were considered as point source participants, based on the scale and availability of data.

We assume that a landowner, potential investor, or some environmental authority would offer to construct wetlands at each of the potential wetland site identified. So the market would include 80 wetland builders.

Digital parcel data were not available for the entire BBC watershed. To include farmers as nonpoint source participants, we considered each square mile section as a single farmer. We used a GIS methodology to identify the nearest downstream node of each "farm" and to estimate each "farmer's" nutrient load on the nearest downstream node. To do this, we used three data sets: township and range section, node-drainage area, and cell area. We ran a spatial intersection on those data sets to calculate the nitrogen and phosphorus loads of each simulated farmer. Using the GIS methodology, we found 4,877 simulated farmers. However, in our market simulations, we omitted 2,085 small-scale farmers who together contributed only $3.7 \%$ of total agricultural runoff. Each of those farms had annual runoff less than $164 \mathrm{~kg}$ $\mathrm{N}$ (with a seasonal average of just $44.8 \mathrm{~kg} \mathrm{~N}$ ). In reality, such small farmers are unlikely to participate in nutrient trading under any scenario. We considered the remaining 2,792 "farmers" as market participants.

Again, our assumptions about identifying traders is not a weakness of our market design, but only of our data for this case. 


\subsection{BBC nutrient reduction costs, bids and offers}

Traders' bids and offers, in a competitive market as this one is expected to be, would be close to traders' marginal costs of nutrient reduction. Though there is no way to obtain accurate cost data, and the participants may have incentive to disguise those data, we estimated the costs based on considerable analysis. These estimates are of varying quality. This data would not be needed in the market, because traders would calculate their own costs based on their private data. We need to estimate traders' marginal costs only to simulate the market for this paper.

The wetland design and construction cost data were from the Iowa Conservation Reserve Enhancement Program (IDALS 2012). These data were used to calculate a regression equation to estimate the total capital cost for each of the 80 potential wetland sites, including an opportunity cost: Total Cost $(\$)=817 \mathrm{X}$ (acres) $+\$ 128,125$. (See Lentz et al. 2013; TWI 2014.) These costs and the seasonal wetland removal data are in TWI (2014) - Appendix A. We assumed that a builder could control only the general wetland configuration, not nitrogen or phosphorus attenuated by season beyond that configuration. We expect these cost estimates to be at the high-end, as they are conservative in design and construction aspects, and the wetlands are expected to have at least a 150 year design life.

For farmers' nutrient reduction costs, we have less assurance in our data, as agricultural BMPs have a range of nutrient reduction efficiencies and costs. We determined the farmer offers based on both Natural Resources Conservation Service (NRCS) payment rates and the data available in literature (Newburn and Woodward 2012; Talberth et al. 2010; US EPA 2007b).

We used a single offer for each farmer and for each nutrient, TN and TP, assuming that the large number of traders would still provide a good indication of trading activity. For each farmer and each season, we randomly selected the offer price for nitrogen reduction from a 
uniform distribution: $\mathrm{U}[\$ 1.64 / \mathrm{kg}$ TN , $\$ 2.22 / \mathrm{kg}$ TN]. Similarly we selected the phosphorus offer prices from a uniform distribution: U[\$8.73/kg TP, $\$ 11.81 / \mathrm{kg}$ TP]. Based on the AnnAGNPS baseline scenario simulation, we calculated farmers' offer quantities assuming that each farmer could reduce TN and TP runoff up to two-thirds of her current runoff in each season (in order to maintain agricultural productivity, farmers have to apply some amount of nutrients). Table 2 shows the offers for five simulated farmers.

Table 2. Market offer data for TN and TP for five example simulated farmers.

\begin{tabular}{|c|c|c|c|c|c|c|}
\hline Parameter & Season & $\mathrm{S} 10$ & S11A & S12 & $\mathrm{S} 2$ & S11B \\
\hline \multirow[t]{4}{*}{ TN current runoff, $\mathrm{kg}$} & Winter & 100.9 & 30.8 & 20.6 & 21.6 & 62.3 \\
\hline & Spring & 350.1 & 94.0 & 76.4 & 95.6 & 246.5 \\
\hline & Summer & 251.3 & 77.3 & 56.6 & 91.6 & 204.9 \\
\hline & Autumn & 163.9 & 55.6 & 37.2 & 51.1 & 125.4 \\
\hline \multirow[t]{4}{*}{ Offer price $\$ / \mathrm{kg}$ TP } & Winter & $\$ 1.80$ & $\$ 1.71$ & $\$ 2.10$ & $\$ 1.72$ & $\$ 1.68$ \\
\hline & Spring & $\$ 1.83$ & $\$ 2.22$ & $\$ 1.82$ & $\$ 1.89$ & $\$ 2.06$ \\
\hline & Summer & $\$ 1.64$ & $\$ 1.80$ & $\$ 1.92$ & $\$ 1.97$ & $\$ 1.72$ \\
\hline & Autumn & $\$ 2.14$ & $\$ 2.17$ & $\$ 2.16$ & $\$ 2.18$ & $\$ 1.93$ \\
\hline \multirow[t]{4}{*}{ TP Current runoff, kg } & Winter & 9.6 & 8.9 & 2.3 & 2.2 & 6.8 \\
\hline & Spring & 37.8 & 24.3 & 8.1 & 15.0 & 31.2 \\
\hline & Summer & 30.9 & 19.7 & 6.4 & 13.3 & 26.3 \\
\hline & Autumn & 14.8 & 14.0 & 3.4 & 4.2 & 10.8 \\
\hline \multirow[t]{4}{*}{ Offer price, $\$ / \mathrm{kg}$ TP } & Winter & $\$ 11.77$ & $\$ 10.50$ & $\$ 9.38$ & $\$ 9.04$ & $\$ 9.21$ \\
\hline & Spring & $\$ 9.99$ & $\$ 9.70$ & $\$ 11.41$ & $\$ 10.73$ & $\$ 9.56$ \\
\hline & Summer & $\$ 11.55$ & $\$ 11.58$ & $\$ 11.43$ & $\$ 11.21$ & $\$ 10.52$ \\
\hline & Autumn & $\$ 9.71$ & $\$ 8.80$ & $\$ 10.63$ & $\$ 8.96$ & $\$ 9.71$ \\
\hline
\end{tabular}

We determined the nutrient load reduction opportunities available for WWTPs based on the technology based effluent limits. We assumed that each WWTP could control nitrogen and phosphorus independently, and the cost of nutrient reduction would be the same for each season. Table 3 contains the estimated effluent discharge and the estimated cost of reduction at each WWTP. While the market design allows all point and nonpoint source traders to submit multiple bids/offers, for simplicity, we assumed that each WWTP would submit a single bid or offer. 
Table 3. Estimated seasonal effluent discharge and bids/offers for the 9 WWTPs.

\begin{tabular}{|c|c|c|c|c|c|c|c|c|c|}
\hline \multirow[b]{2}{*}{ Parameter } & \multirow[b]{2}{*}{ Ohio P1 } & LaMoille & Malden & \multicolumn{2}{|c|}{ Maple Princeton } & \multirow{2}{*}{$\begin{array}{r}\text { Wyanet } \\
\text { P6 }\end{array}$} & \multirow{2}{*}{$\begin{array}{r}\text { Prairie } \\
\text { P7 }\end{array}$} & \multicolumn{2}{|c|}{ Aspirie Tiskilwa } \\
\hline & & $\mathrm{P} 2$ & P3 & $\mathrm{P} 4$ & P5 & & & P8 & P9 \\
\hline Winter discharge TN, kg & 76.7 & 63.1 & 50.0 & 25.9 & 4245.0 & 250.2 & 20.0 & 50.0 & 120.1 \\
\hline Spring discharge $\mathrm{TN}, \mathrm{kg}$ & 78.2 & 64.3 & 51.0 & 26.4 & 4327.3 & 255.1 & 20.4 & 51.0 & 122.4 \\
\hline $\mathrm{r}$ discharge $\mathrm{TN}, \mathrm{kg}$ & 78.2 & 64.3 & 51.0 & 26.4 & 4327.3 & 255.1 & 20.4 & 51.0 & 122.4 \\
\hline Autumn discharge TN, kg & 77.3 & 63.6 & 50.5 & 26.1 & 4280.3 & 252.3 & 20.2 & 50.5 & 121.1 \\
\hline TN bid/offer price, $\$ / \mathrm{kg}$ & $\$ 74.68$ & $\$ 87.78$ & $\$ 107.08$ & $\$ 194.66$ & $\$ 37.87$ & $\$ 35.25$ & $\$ 248.41$ & $\$ 107.08$ & $\$ 53.12$ \\
\hline Winter discharge TP, $\mathrm{kg}$ & 32.2 & 26.5 & 21.0 & 10.9 & 374.6 & 105.0 & 8.4 & 21.0 & 50.4 \\
\hline Spring discharge TP, $\mathrm{kg}$ & 32.8 & 27.0 & 21.4 & 11.1 & 381.8 & 107.1 & 8.6 & 21.4 & 51.4 \\
\hline Summer discharge TP, kg & 32.8 & 27.0 & 21.4 & 11.1 & 381.8 & 107.1 & 8.6 & 21.4 & 51.4 \\
\hline Autumn discharge TP, $\mathrm{kg}$ & 32.5 & 26.7 & 21.2 & 11.0 & 377.7 & 105.9 & 8.5 & 21.2 & 50.8 \\
\hline TP bid/offer price, $\$ / \mathrm{kg}$ & $\$ 31.99$ & $\$ 37.44$ & $\$ 45.44$ & $\$ 81.48$ & $\$ 5.12$ & $\$ 14.45$ & $\$ 103.53$ & $\$ 45.44$ & $\$ 22.84$ \\
\hline
\end{tabular}

\section{Results and Discussion}

We simulated the proposed market for the BBC watershed under two scenarios. First, for comparison purposes, we simulated a base case of trading between WWTPs and wetlands. Second, we simulated a full multilateral trading case with all nine WWTPs, 80 potential wetland sites, and 2,792 simulated farmers.

\subsection{Base Case: trade between WWTPs and wetlands}

This scenario simulates potential trading activity only between WWTPs and wetlands. In this case, we assumed that the current nutrient loads at the outlet have to be reduced by an amount equal to the total WWTP runoff at the outlet, which is less than $1 \%$ of the total runoff from all sources (so $\alpha=99 \%$ ), and the initial allocations of all WWTPs in the optimization model were set zero. Upstream wetlands could provide reductions to allow the WWTP to avoid reducing its loads to zero and discharge at its current level. This scenario assumes that the farmers will not participate in trading and they will not reduce their nutrient discharges. However, a wetland could attenuate upstream farmers' load so that the downstream WWTPs do not have to reduce their own discharges. Trading would not always require the wetlands to 
attenuate WWTP nutrient loads directly; the market manager could accept wetland offers to offset upstream nutrient loads from other sources.

The simulation results for this base case indicated little trading. The wetlands provided credits to meet $100 \%$ of the WWTP load reductions required to meet the hypothetical effluent limit (for both TN and TP), as measured at the outlet. Figure 3 shows a diagram of the result for TN. Only two wetlands were needed, Wetland 851 and Wetland 796, both proposed upstream of several WWTPs. The accepted wetlands are relatively small and have relatively higher nutrient removal efficiencies. While the wetland offers were fully accepted, total WWTP demand could be met with only a portion of those wetlands. This over-supply depressed nodal prices to zero.

Figure 3. Central part of the BBC watershed, for trade between WWTPs and wetlands. Segment width indicates TN quantity. Wetlands are green, at upper right. The black circles correspond to WWTPs. Nodal prices are all zero. The outlet is bottom center. The two wetland builders would be paid at their offer prices of $\$ 148,176$ and $\$ 140,340$ respectively, for a total cost of only $\$ 288,516$, for a 10 -year period (as discussed in section 3.2, these amounts correspond to the respective start-up payments). The total cost is only $32.7 \%$ of the cost that the WWTPs together bid to buy nutrient credits. While this would be a huge savings from the point of view of the WWTP managers, this outcome barely dents the total runoff from the watershed. Note that even $100 \%$ of total WWTP required load reduction is a small reduction for the watershed as a whole, less than $1 \%$ of the total nutrient runoff. This base case illustrates that with WWTP demand alone, nutrient trading would be thin, and would not even achieve $1 \%$ of nutrient reduction at the BBC outlet. 


\subsection{All participant trading case}

In this case, we simulated a single-sided auction in which the market manager, on behalf of a local environmental authority, is calling offers to buy nutrient reductions to meet a prespecified load reduction target at the assessment point at minimum cost. This scenario takes into account farmers' offers to reduce nutrients. We assumed that the farmers would offer to reduce nutrients by two-thirds of their current runoff. The wetland offers would now compete with farmers' and WWTP offers. We solved the market clearing optimization considering a range of hypothetical allowance levels (fractions of current load allowed), e.g., 0\%, 20\%, $40 \%, 50 \%, 60 \%, 80 \%$, and $100 \%$. (In the linear program, the allowance level is $\alpha$, and the respective target reduction is $1-\alpha$.

As an illustration, we first present the results for the $50 \%$ reduction $(\alpha=0.5)$ scenario. Figures 4 and 5 show the distribution of TN credit prices, the wetlands to be implemented, and TN levels throughout the upper and lower parts of the watershed in winter. As shown in Figure 5, the cleared price for $1 \mathrm{~kg}$ TN reduction at the BBC outlet (farthest downstream node) is \$1.99. Since we assumed negligible in-stream attenuation factors, several upstream nodes have the same price.

For the $50 \%$ reduction $(\alpha=0.5)$ case, the upstream prices are lower in some parts of the watershed owing to natural in-stream attenuation. Of the proposed 80 wetlands, 23 were selected. The selected wetlands were scattered all over the watershed, but the majority were upstream owing to the ability of those wetlands to capture nutrient discharges from agricultural nonpoint sources. The selected wetlands have relatively higher removal rates for both nitrogen and phosphorus compared to others.

Figure 4. The nodal prices (\$/ kg TN) in the upper central part of the BBC catchment for the $50 \%$ reduction $(\alpha=0.5)$ case. Segment width indicates nitrogen quantity and the 
green segments are wetlands. Orange dots are WWTPs. The nodes with no prices shown have price zero.

Figure 5. The nodal prices $(\$ / \mathrm{kg} \mathrm{TN})$ in the central BBC catchment downstream of Princeton for the $50 \%$ reduction $(\alpha=0.5)$ case. Segment width indicates nitrogen quantity and the green segments are wetlands. Orange dots are WWTPs. The nodes with no prices shown have price zero.

Nineteen of the selected wetlands would receive more than their offer price, in some cases much more (Table 3). The total payment to these 19 traders with accepted wetlands was $\$ 7,561,500$, almost twice their collective offer at $\$ 3,963,200$. These results indicate that the wetland builders would make approximately a $100 \%$ return (a fixed 10 -year profit) on their investment in nutrient removal wetlands. The reason is that the demand (for 50\% nutrient load reduction) has raised the market value of wetlands. The wetland builders must be paid at least the market price of nitrogen and phosphorus reductions. The reduction payment due for each of the other four wetlands is not sufficient to cover the price of the offers. For those wetland builders, the start-up payment covers the deficiency. As mentioned above, full acceptance of partially required wetlands create an over-supply, which then depresses prices locally.

The only WWTP offers accepted were from the Princeton WWTP and only for phosphorus. The Princeton offer for phosphorus had by far the lowest price compared to any farmer or WWTP.

With 2,792 farmers submitting offers for nitrogen and phosphorus and for four seasons separately, we had 22,336 farmer offers in the auction. Nearly all farmers traded nitrogen and/or phosphorus credits at least in some season. Only 3.4\% of participating farmers (by count) had no BMP offer accepted for any season. However, of the 11,168 nonpoint source offers for nitrogen, only 5,130 offers were accepted. Of the 11,168 offers for phosphorus, 
only 5,084 offers were accepted. The results indicate that the farmers can make economic gains from even short-term nutrient reductions, in just one season. The total payment to the farmers with accepted offers was $\$ 23,261,173$. This is approximately $75 \%$ of the total cost of achieving a 50\% reduction of nutrient load at the BBC outlet. Though our estimates of farmers' nutrient reduction costs were at the high end, farm level nutrient reductions still seem to be economical.

Table 3. Offers, 10-year prices, and attenuation payments, start-up payments, the final payment, and the profit for the accepted wetlands with the $50 \%$ runoff allowance constraint.

\begin{tabular}{|c|c|c|c|c|c|c|c|c|c|c|c|c|}
\hline \multirow{2}{*}{\multicolumn{2}{|c|}{$\begin{array}{r}\text { Offer } \\
\text { price }\end{array}$}} & \multicolumn{4}{|c|}{$\begin{array}{c}\text { Nitrogen credit price } \\
\qquad / \mathrm{kg} \text { TN }\end{array}$} & \multicolumn{3}{|c|}{$\begin{array}{l}\text { Phosphorus credit price } \\
\qquad / \mathrm{kg} \text { TP }\end{array}$} & \multirow{2}{*}{$\begin{array}{r}\text { Atten } \\
\text { paymt } \\
\$\end{array}$} & \multirow{2}{*}{$\begin{array}{r}\text { Start-up } \\
\$\end{array}$} & \multirow{2}{*}{\multicolumn{2}{|c|}{$\begin{array}{r}\text { Final } \\
\text { paymt } \\
\$\end{array}$}} \\
\hline & & Win & Spr & $n$ & Aut & n & Spr & Aut & & & & \\
\hline W1561 & 159,530 & 9.94 & 19.57 & 19.56 & 9.99 & 106.23 & 06.69105 .54 & 106.59 & 475,476 & 0 & 475,476 & ,946 \\
\hline 201 & 177,379 & 17.75 & 19.38 & 19.36 & 18.65 & 105.14 & 104.57103 .45 & 104.72 & 608,071 & 0 & 608,071 & 430,692 \\
\hline 8 & 70 & 9.94 & 18.43 & 18.4 & 19.59 & 106.23 & $96.03 \quad 95.00$ & 5.00 & 145,988 & 0 & 150 & 7818 \\
\hline 95 & 020 & 5.90 & 18.17 & 18.41 & 7.72 & 101.59 & $97.00 \quad 95.95$ & 100.64 & 83,460 & 0 & 183,46 & 29,440 \\
\hline 35 & 171,609 & 17.61 & 16.66 & 16.65 & 19.01 & 106.2 & 93.1992 .18 & 02.40 & 75,053 & 0 & 275,053 & 444 \\
\hline 620 & 358,397 & 0.00 & 16.17 & 16.1 & 0.00 & 0.00 & $0.00 \quad 90.81$ & 87.44 & 872 & 0 & 421,8 & 63,475 \\
\hline 2 & 148 & 19.94 & 18.2 & 18. & 19.64 & 106.23 & $87.75 \quad 86.80$ & 104.74 & F & 0 & $2+3$ & 95 \\
\hline 96 & 154 & 94 & 17.35 & 17.34 & 19.30 & 106.23 & $85.57 \quad 84.65$ & 103.43 & & 0 & 302,9 & 30 \\
\hline 245 & 43 & 9.94 & 16.01 & 16.00 & 18.58 & 106.23 & $\begin{array}{ll}78.58 & 77.74\end{array}$ & 01.38 & 500 & 0 & 165,500 & 24,357 \\
\hline 660 & 8 & 0.00 & 15.53 & 0. & 0.00 & 0.00 & $0.00 \quad 81.73$ & 0.00 & 86,678 & 40 & 210 & 0 \\
\hline 85 & 104 & 19.94 & 18.24 & 18.23 & 19.64 & 06.23 & $92.26 \quad 91.26$ & 104.74 & 36 & 0 & $4 / 0,0$ & $05,9<0$ \\
\hline 90 & 67,186 & 17.30 & 19.38 & 19.36 & 18.57 & 103.13 & $99.46 \quad 98.39$ & 105.05 & 293,066 & 0 & 293,006 & 125,880 \\
\hline 32 & 50 & 0.00 & 19.30 & 1.24 & 16.54 & 0.00 & 95.91111 .47 & 0.00 & 90 & 60 & 189,5 & 0 \\
\hline 851 & 148,176 & 0.00 & 17.59 & 17.89 & 16.55 & 91.32 & $95.02 \quad 95.10$ & 0.00 & 848,921 & 0 & 848,92 & 700,745 \\
\hline 96 & 140 & 0.00 & 17.42 & 17.71 & 16.50 & 91.32 & $93.13 \quad 93.21$ & 0.00 & 758 & 0 & 178,7 & 38,417 \\
\hline 07 & 195 & 0.00 & 0.00 & $0 .($ & 0.00 & 0.00 & 0.00 & 0.00 & 0 & & & 0 \\
\hline 1120 & 172,102 & 17.98 & 19.52 & 20.16 & 19.11 & 106.23 & 109.95108 .76 & 107.39 & 451,748 & 0 & 451,748 & 279,646 \\
\hline 389 & 163,133 & 16.62 & 20.62 & 19.55 & 17.40 & 90.91 & 99.53105 .33 & 100.56 & 202,997 & 0 & 202,9 & 39,86 \\
\hline W1124 & 158,979 & 18.30 & 20.31 & 20.57 & 19.39 & 106.23 & 111.06109 .86 & 107.93 & 461,841 & 0 & 461,8 & 302,863 \\
\hline V891 & 152,759 & 19.61 & 20.17 & 20.16 & 18.95 & 106.23 & 105.10103 .97 & 106.78 & 301,495 & 0 & 301,4 & 148,735 \\
\hline W770 & 170,578 & 18.00 & 19.97 & 19.96 & 18.88 & 101.15 & 103.01101 .90 & 104.28 & 514,920 & 0 & 514,920 & 344,342 \\
\hline
\end{tabular}




\begin{tabular}{rr|rrrr|r|r|r|r|r|r|r|r}
\hline W755 & 158,514 & 0.00 & 17.51 & 17.29 & 0.00 & 95.15 & 102.50 & 101.39 & 103.76 & 250,865 & 0 & 250,865 & 92,351 \\
\hline W737 & 168,414 & 0.00 & 17.51 & 16.81 & 0.00 & 93.28 & 92.63 & 90.32 & 103.69 & 154,900 & 13,513 & 168,414 & 0 \\
\hline
\end{tabular}

To summarize the solutions for varying levels of reduction requirements, the number of wetlands accepted for $20 \%(\alpha=0.8), 40 \%(\alpha=0.6), 50 \%(\alpha=0.5)$, and 60\% $(\alpha=0.4)$ reductions were $3,22,23$ and 23 respectively. As expected, zero reduction requirement $(\alpha=1)$ has costs equal to $\$ 0$ with all prices were at $\$ 0 / \mathrm{kg}$, and no offers were accepted. The $80 \%$ reduction case $(\alpha=0.2)$, at the extreme opposite, is infeasible. This infeasibility implies that, even if the farmers are willing to reduce their nutrient discharges by two-thirds (maximum) and all the proposed wetlands are implemented, the total nutrient load at the watershed outlet cannot be reduced by $80 \%$ or more.

The three wetlands accepted under all scenarios, Wetland 1201, Wetland 885 and Wetland 851 have the highest nutrient removal efficiencies. The credit prices and the required number of wetlands increase when the runoff constraint is tightened by reducing the percentage of current load allowed. The same 23 wetlands required to meet the $50 \%$ allowance constraint were sufficient to meet the $40 \%$ allowance constraint. Some wetlands were overbuilt under $50 \%$ allowance constraint. The solution for the $40 \%$ allowance constraint (compared to 50\%) indicates that dynamic farm level BMPs are more economical than another wetland.

Figure 6 shows a graph of total cost (total payments from the market manager to all participants) versus percent of current runoff allowed. Note that this cost is a total 10 -year cost, not an annual cost. A $40 \%$ load reduction would cost approximately $\$ 20$ million over a 10-year period. In recent years, the U.S. government has spent billions of dollars on agricultural conservation (Claassen et al., 2014). Targeted federal conservation funding for purchasing nitrogen and phosphorus credits might be best utilized through a smart market such as this one. 
Figure 6. Graph of the total 10-year cost versus \% current runoff allowed.

\section{Conclusions, further work and recommendations for policy}

Nutrient credit trading with wetlands is a complicated common-pool commodity trading problem which requires proper market design. Conventionally, regulators have used trading ratios to account for the complex and uncertain interactions in the underlying physical systems of nutrient fate and transport. We propose a smart market as a better design for nutrient trading, and we have shown that a smart market can incentivize wetland builders to participate as credit suppliers. The smart market takes into account relevant hydro-geological information in determining locational prices which match demand and supply. We simulated the proposed market design for the $\mathrm{BBC}$ watershed with relevant scientific and economic data.

Our results indicate that WWTPs, wetland builders, and farmers together can create an active nutrient market in BBC leading to significant reductions in nutrient runoff. Wetlands and farm level BMPs seem to dominate the market, and WWTPs play a minor role from both demand and supply perspectives. In agricultural watersheds like the BBC, demand from WWTPs is not enough to create an active market of nutrient credits nor to realize significant nutrient reduction. We observed that even a few strategically-placed small wetlands can effectively offset the nutrient loads of several WWTPs, providing significant cost savings to WWTPS. The proposed market select wetland locations strategically taking into account both cost and nutrient reduction efficiencies. Owing to the lumpiness and long-term nature of wetland investments, potential cost savings from some wetlands can be forgone, leaving space for more dynamic farm level BMPs. Therefore, we emphasize the importance of farmer participation in nutrient trading together with wetlands. 
The market design is quite general. It could work for other pollutants and combinations of pollutants (e.g., biological oxygen demand, temperature, sediment, etc.) and for any segmentbased configuration of streams, constructed wetlands, or other BMPs. The trading ratio nutrient trading systems do not consider the stream network configurations and attenuations as accurately as we have done in our market design.

The proposed nutrient market can be improved by relaxing the "all-or-nothing" requirement associated with wetland offers. Wetland offers could be partially accepted if wetland configurations could be more dynamically adjusted. This would eliminate the need for startup payments ensuring a revenue neutral auction. In the market clearing optimization model, we used deterministic estimates of seasonal nutrient runoff and absorption. Owing to the uncertainty in these estimates, a stochastic optimization model, with different scenarios by season, may be more appropriate. Finally, rather than bidding/offering explicitly for nitrogen or phosphorus reductions, traders could bid/offer for various land uses or operations. To the extent that these land uses affect both nitrogen and phosphorus loss, such a market for land use permits have the capacity to handle the problem of credit stacking pointed out by Lentz et al (2013).

However, like other long term land use commitments, investment in wetland construction incorporates risk. Demand for credits from the wetland may diminish before the end of the investor's planning horizon. New abatement technology and eco-friendly farming methods may emerge, reducing the demand for wetlands. As mentioned earlier, in addition to nutrient removal, wetlands provide other ecosystem services such as improvement of ecological habitat. If those services are also internalized into a more dynamic multi commodity market, investors would be further incentivized to construct wetlands.

Should investors want a longer term of assurance, they could attempt to negotiate for a longer auction term, say, 15 years instead of 10 . While the proposed market allows trading futures 
for a relatively longer period, the participants can decide themselves how long into the future they should buy. The decision depends on each participant's risk perception and price forecasts. They may want assurance that the cap or TMDL remains constant. In any case, this risk is not a fault of the market; it is simply the nature of investment.

We hope that policy makers take this work as an important proof of concept. Our findings should encourage stakeholders learn more about the viability of WQT with wetlands, to take part in market implementation, and to participate in trading. Our study provided insights about the economic, hydrogeological, and regulatory concerns to be addressed in trading program design. Trial implementation at watershed or sub-watershed scale would enable the policymakers to test our results. We recognize the political hurdles involved in implementation, and the need for close monitoring and enforcement. But if implemented correctly, with appropriate TMDLs and specifications, the smart market would reduce nutrient loadings at what appears to be the lowest cost possible.

\section{Acknowledgements}

We thank Jim Monchak at the Wetlands Initiative and Dr. Ron Bingner at the USDA Agricultural Research Service, National Sedimentation Laboratory for their contributions to this work. This work was supported by the U.S. Environmental Protection Agency Targeted Watershed Grant WS-00E71101 and the Wetlands Initiative. The first two authors were at the University of Canterbury, Christchurch, New Zealand, when the work began.

\section{References}

Carlson, B., Y. Chen, M. Hong, R. Jones, K. Larson, X. Ma, P. Nieuwesteeg, H. Song, K. Sperry, M. Tackett, D.Taylor, J.Wan, and E. Zak. 2012. MISO unlocks billions in savings through the application of operations research for energy and ancillary services markets. Interfaces 42(1): 5873. 
Claassen, R., J. Horowitz, E. Duquette, and K. Ueda. Additionality in U.S. Agricultural

Conservation and Regulatory Offset Programs, ERR-170, U.S. Department of Agriculture, Economic Research Service, July 2014

Cramton, P. and Stoft, S. 2008. Forward reliability markets: Less risk, less market power, more efficiency. Utilities Policy 16(3): 194-201.

Crumpton, W.G., G.A. Stenback, B.A. Miller, and M.J. Helmers. 2006. Potential benefits of wetland filters for tile drainage systems: Impact on nitrate loads to Mississippi River subbasins. Washington, DC: U.S. Department of Agriculture.

David, E. L. 2003. Marketable water pollution permits as economic incentives: Point source trading in Wisconsin. Presented at the Inter-American Development Bank Technical Seminar on the Application of Economic Instruments in Water Management, Washington, D.C.

Environmental Protection Authority. 2003. Hunter River Salinity Trading Scheme: Working together to protect river quality and sustain economic development. Australia: Environmental Protection Authority, Department of Environment and Conservation (NSW).

Faeth, P. 2000. Fertile ground: Nutrient trading's potential to cost effective improve water quality. Washington, DC: World Resource Institute. http://www.wri.org/publication/fertileground (accessed May 23, 2010).

Gabriel, S.A., S. Kiet, and J. Zhuang. 2005. A mixed complementarity-based equilibrium model of natural gas markets. Oper. Res. 53 (5): 799-818.

Heberling, M.T., J.H. Garcíab, H.W. Thurston. 2010. Does encouraging the use of wetlands in water quality trading programs make economic sense? Ecol. Econ. 69(10):1988-1994.

Hey, D. L., J. A. Kostel, A. P. Hurter, and R. H. Kadlec. 2005. Comparing economics of nitrogen farming with traditional removal. WERF 03-WSM-6CO. Alexandria, VA: Water Environment Research Foundation. 
Hoag, D. L., and J. S. Hughes-Popp. 1997. Theory and practice of pollution credit trading in water quality management. Rev. Agr. Econ. 19(2): 252-262.

Hobbs, B.F. 2001. Linear complementarity models of Nash-Cournot competition in bilateral and POOLCO power markets. IEEE T. Power Syst. 16(2): 194-202.

Horan, R.D., J.S. Shortle, and D.G. Abler. 2002. Point-nonpoint source nutrient trading in the Susquehanna River Basin. Water Resour. Res. 38(5):8.1 - 8.12

Horan, R. D., Abler, D. G., Shortle, J. S. and Carmichael, J. 2002. Cost-effective point-nonpoint trading: an application to the Susquehanna River Basin. J. Am. Water Resour. As. 38(2): 467477.

Hung, M.-F., and D. Shaw. 2005. A trading-ratio system for trading water pollution discharge permits. J. Environ. Econ. Manag. 49(1): 83-102.

Kadlec, R. H., and R. L. Knight. 1996. Treatment wetlands. New York: CRC Lewis Publishers.

Kadlec, R. H., and S. D. Wallace. 2008. Treatment wetlands. 2nd. ed. Boca Raton: CRC Press.

King, D. M., and P. J. Kuch. 2003. Will nutrient credit trading ever work? An assessment of supply and demand problems and institutional obstacles. Environmental Law Reporter: News and Analysis 33 ELR 5-2003: 10352-10368.

Lentz, A. 2011a. Physical criteria for wetland targeting on a watershed scale. M.S. thesis, University of Illinois at Urbana-Champaign.

Lentz, A. 2011b. Water Quality Trading: Credit stacking and ancillary benefits. University of Illinois at Urbana-Champaign M.S. Thesis.

Lentz, A.T.B., A. W. Ando and N. Brozovic. 2013. Water quality trading with lumpy investments, credit stacking, and ancillary benefits. J. Am. Water Resour. As. 50(1): 83-100. 
Liao, Chao-ning, Hayri Önal and Ming-Hsiang Chen. 2009. Average shadow price and equilibrium price: A case study of tradable pollution permit markets. Eur. J. Oper. Res. 196 (3): $1207-1213$.

Lock, K., and S. Kerr. 2008. Nutrient trading in Lake Rotorua: Overview of a prototype system. Motu Working Paper 09-09.

McGartland, A. M. 1988. A comparison of two marketable discharge permit systems. J. Environ. Econ. Manag. 15: 35-44.

McCabe, K. A., S. J. Rassenti, and V. L. Smith. 1991. Smart computer-assisted markets. Science 254(5031): 534-538.

Morgan, C. L., and A. Wolverton. 2005. Water quality trading in the United States. Working Paper 05-07. Washington, DC: National Center for Environmental Economics.

Morgan, C. L., J. S. Coggins, and V. R. Eidman. 2000. Tradable permits for controlling nitrates in groundwater at the farm level: A conceptual model. Journal of Agricultural and Applied Economics 32(2): 249-258.

Newburn, D. 2012. From Ohio to the Chesapeake. Center for Agricultural \& Natural Resource Policy Research Brief Volume 2, Issue 1. Department of Agricultural and Resources Economics, University of Maryland.

Ng, T., J. Eheart, and X. Hu. 2007. Discharge trading programs based on constructed wetlands for nutrient trading. World Environmental and Water Resources Congress. American Society of Civil Engineers. Tampa, Florida, United States, May 15-19, 2007.

Nguyen N. P., J. S. Shortle, P. M., and Reed, and T. T. Nguyen. 2013. Water quality trading with asymmetric information, uncertainty and transaction costs: A stochastic agent-based simulation. Resour. Energy Econ. 35(1): 60-90. 
O’Neill, R.P., P.M. Sotkiewicz, B.F. Hobbs, M.H. Rothkopf and W.R. Stewart Jr., Efficient market-clearing prices in market with nonconvexities. Eur. J Oper. Res. 164 (2005): 269-285.

Prabodanie, R. A. R., J. F. Raffensperger, E. G. Read and M. W. Milke. 2014. LP models for pricing diffuse nitrate discharge permits. Ann. Oper. Res. 220(1): 87-109.

Raffensperger, J. F. 2011. Matching users' rights to available groundwater. Ecol. Econ. 70 (6): 1041-1050.

Rassenti, S.J., V.L. Smith, and R.L. Bulfin. 1982. A combinatorial auction mechanism for airport time slot allocation. Bell J. Econ. 13(2): 402-417.

Reddy K. R., R. H. Kadlec , E. Flaig, and P. M. Gale .1999. Phosphorus retention in streams and wetlands: a review. Critical Reviews in Environmental Science and Technology 29:83-146.

Rothkopf, M. H., A. S. Pekeč., and R. M. Harstad. 1998. Computationally manageable combinational auctions. Manag. Sci. 44(8): 1131-1147.

Samuelson, P.A. 1952. Spatial price equilibrium and linear programming. Am. Econ. Rev. 42(3): 283-303.

Selman, M., S. Greenhalgh, E. Branosky, C. Jones, and J. Guiling. 2009. Water quality trading programs: An international overview. World Resource Institute Issue Brief 1: 1-16.

Shortle, J. 2012. Water Quality Trading in Agriculture. Report prepared the Organization for Economic co-operation and Development (OCED).

COM/TAD/CA/ENV/EPOC(2010)19/FINAL.

Shortle, J. 2013. Economics and environmental markets: Lessons from water-quality trading. Agricultural and Resource Economics Review 42 (1), 57-74.

Stephenson, K. and L. Shabman. 2011. Rhetoric and reality of water quality trading and the potential for market-like reform. J. Am. Water Resour. As. 47(1):15-28. 
Talberth, J., C. Jones, M. Perez, M. Selman, and E. Branosky. 2010. How baywide nutrient trading could be benefit Maryland farms. Washington, DC: World Resources Institute.

The Wetlands Initiative (TWI). 2014. Feasibility Assessment of a Nutrient Trading Market in the Big Bureau Creek Watershed Final Report. Prepared for U.S. Environmental Protection Agency Targeted Watershed Grant WS-00E71101. The Wetlands Initiative, Chicago, IL.

Tomer, M.D., Crumpton, W.G., Bingner, R.L., Kostel, J.A., and James, D.E. 2013. Estimating nitrate load reductions from placing constructed wetlands in a HUC-12 watershed using LiDAR data. Ecol. Eng. 56:69-78.

U.S. Environmental Protection Agency (US EPA). 2000. Ambient water quality criteria recommendations (Information supporting the development of state and tribal nutrient criteria): Rivers and streams in nutrient ecoregion VI. EPA 822-B-00-017. Washington, DC: U.S. Environmental Protection Agency, Office of Water.

U.S. Environmental Protection Agency (US EPA). 2007a. Wetlands and water quality trading: Review of current science and economic practices with selected case studies. EPA 600-R-06-155. July 2007. Washington, DC: U.S. Environmental Protection Agency, Office of Research and Development, National Risk Management Laboratory. nepis.epa.gov/Adobe/PDF/60000LDI.pdf U.S. Environmental Protection Agency (US EPA). 2007b. Water quality trading toolkit for permit writers. EPA 833-R-07-004 Updated June 2009. Washington, DC: U.S. Environmental Protection Agency, Office of Wastewater Management, Water Permits Division.

U.S. Environmental Protection Agency (US EPA). 2008. EPA Water Quality Trading Evaluation - Final Report. EPA's Office of Policy, Economics and Innovation (OPEI). October 2008.

Woods, R., Elliott, S., Shankar, U., Schmidt, J., Bidwell, V., Bright, J., et al. (2004). Predicting the Effects of Landuse on Water Quality - Stage I. A report prepared for the Ministry of Agriculture and Forestry (NIWA Client Report No. CHC2004-097). Christchurch: National Institute of Water \& Atmospheric Research Ltd. 


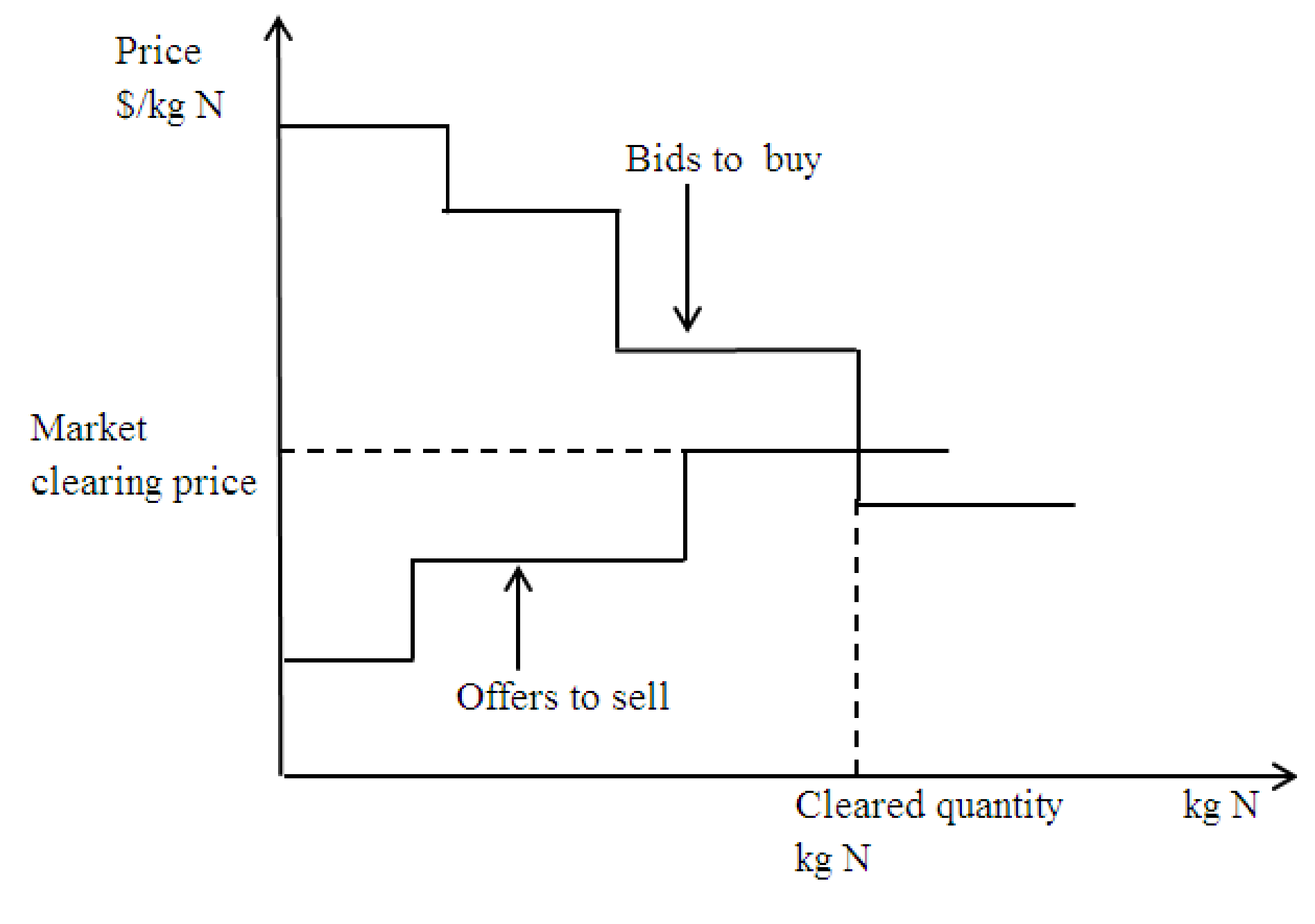

Figure 1 .

Figure 1

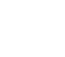

. . 


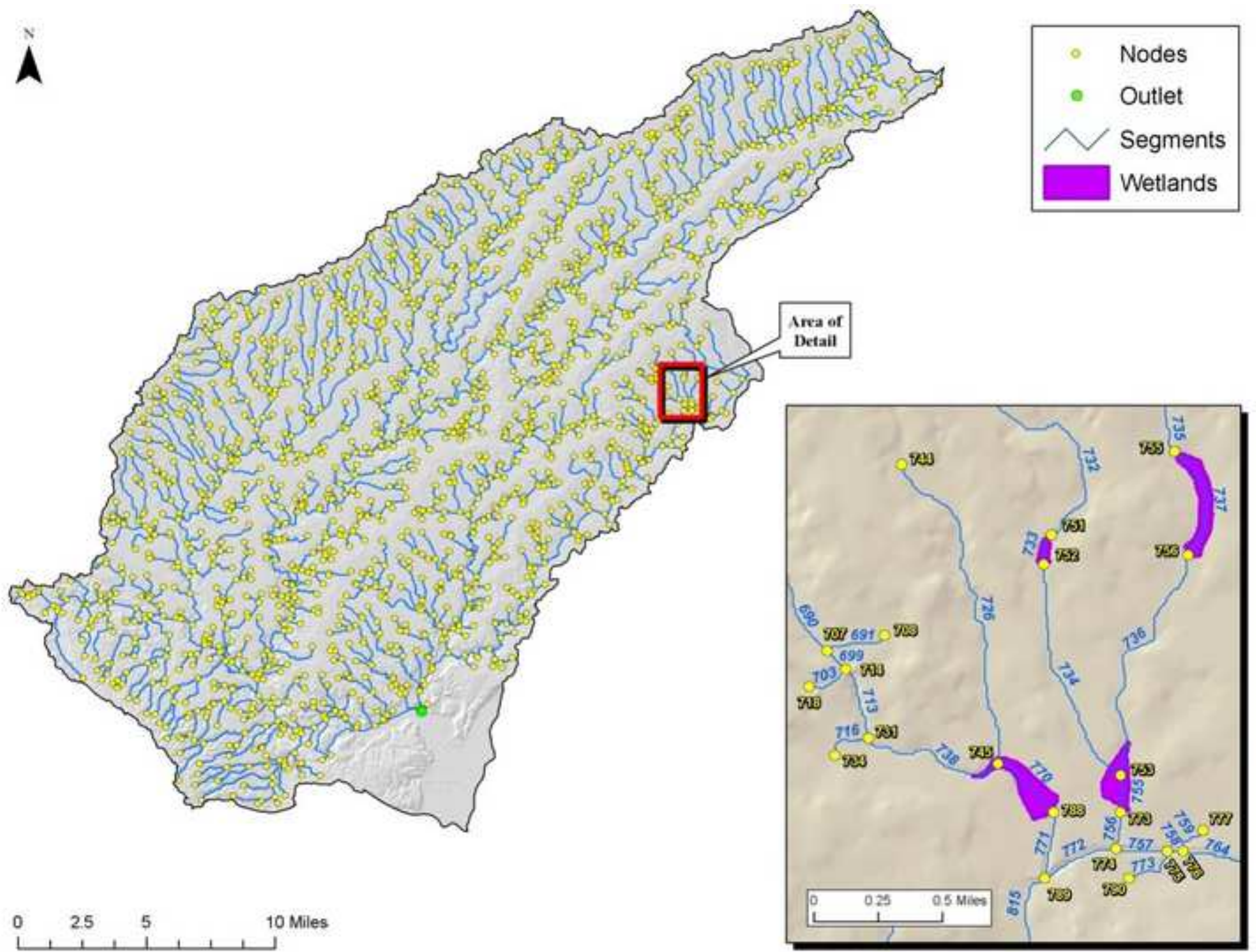

A . 

Figure 4

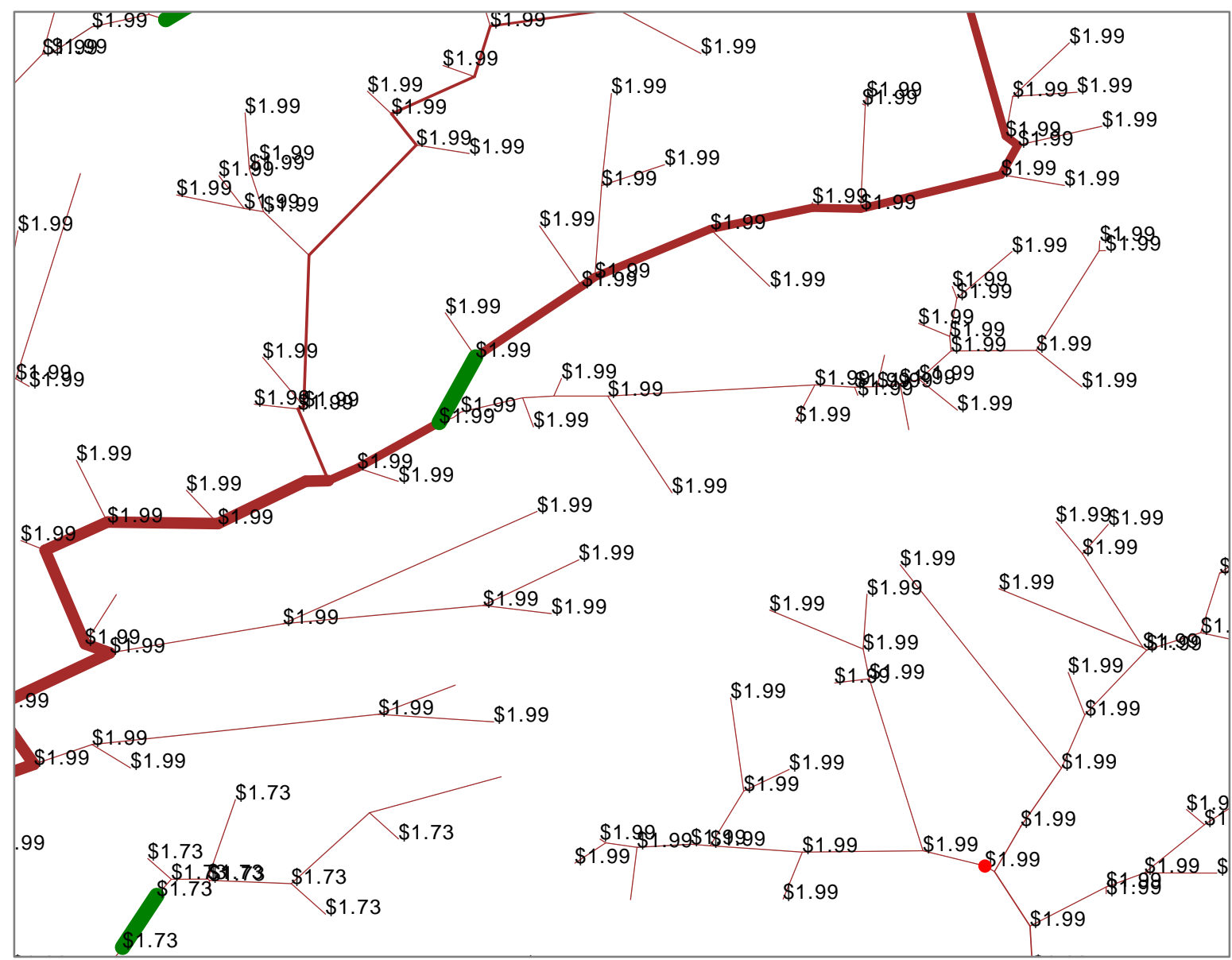




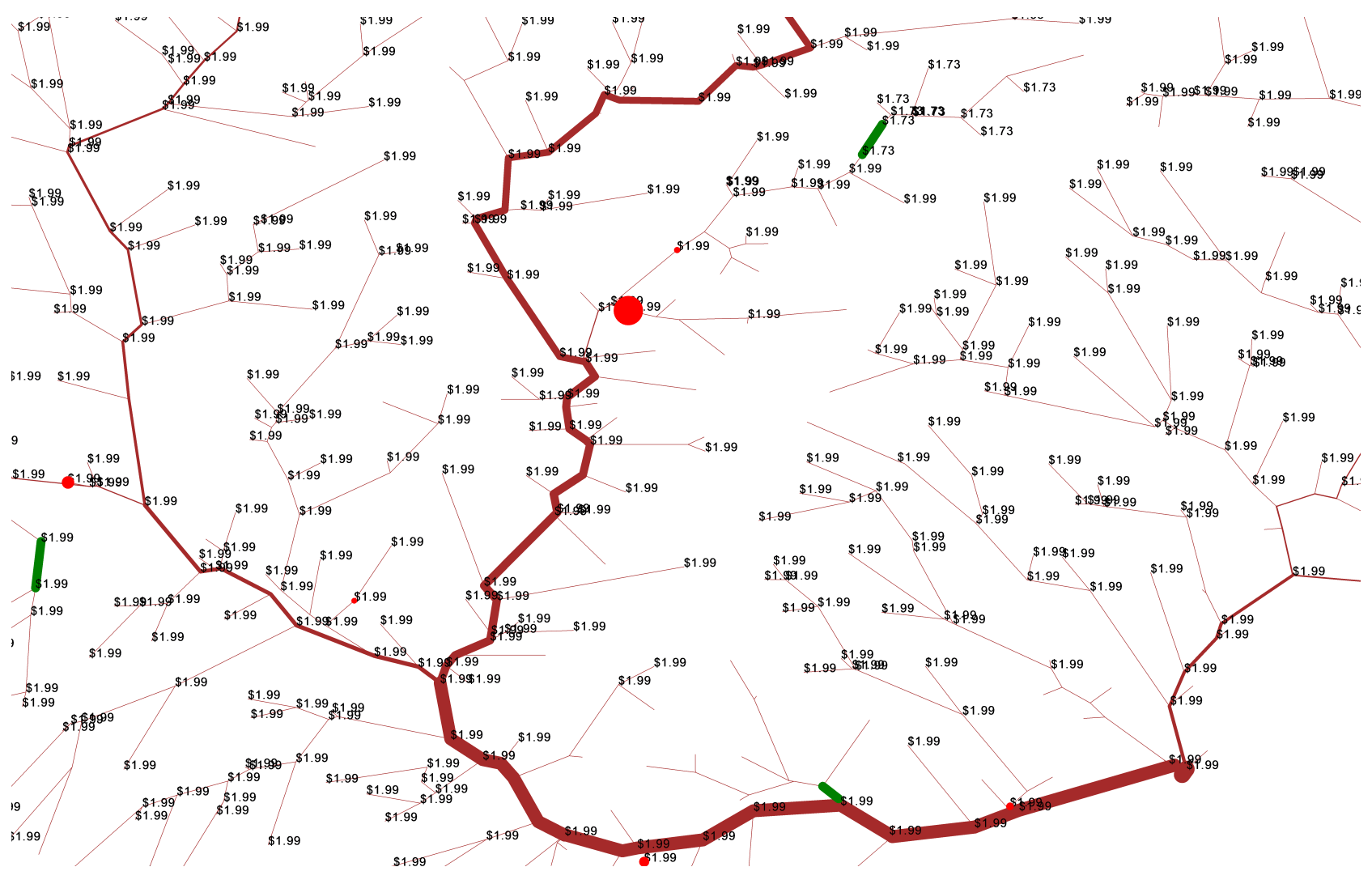


Figure 6

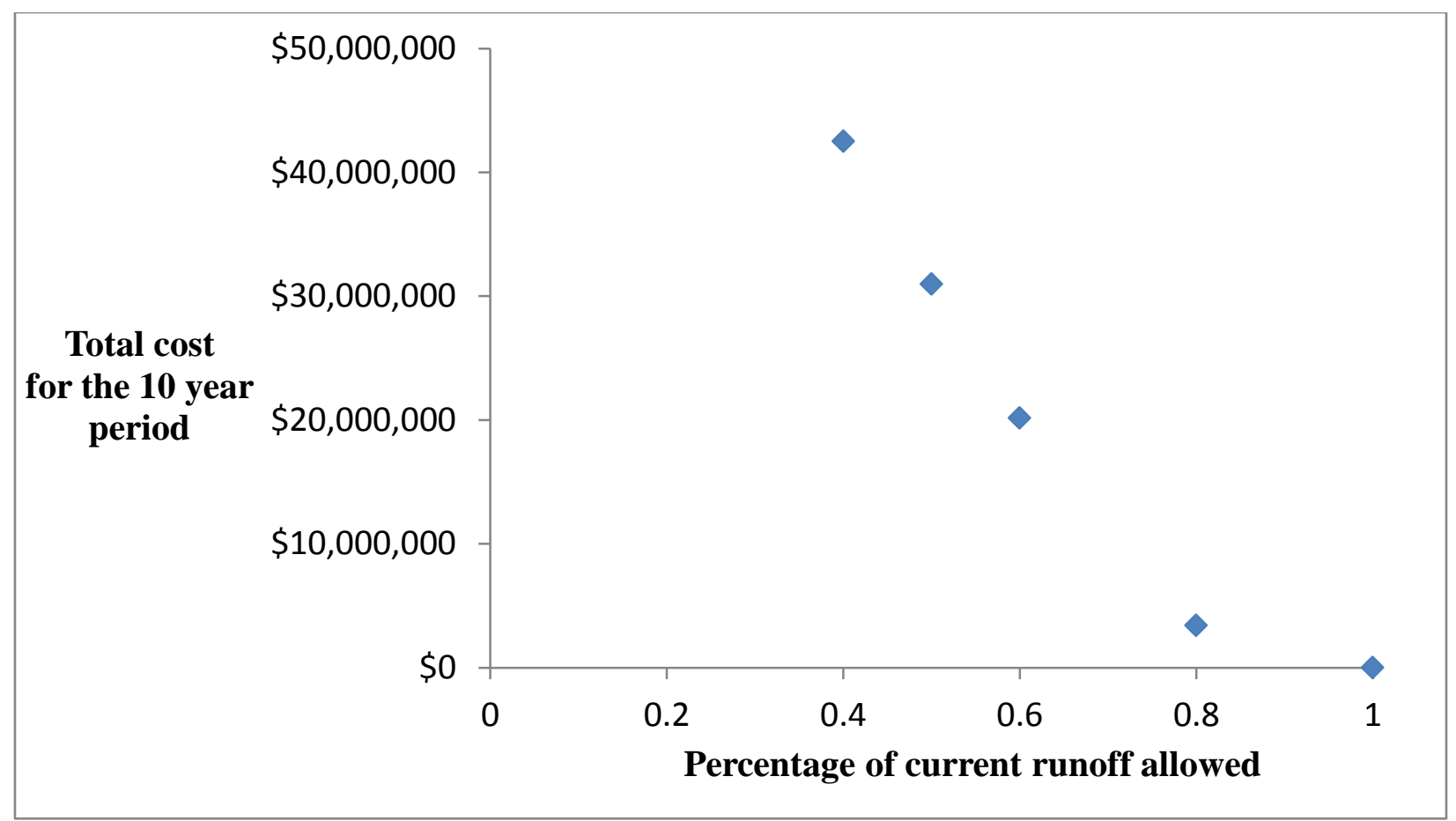

